\title{
SOME RESULTS ON FIXED POINT THEOREMS FOR MULTIVALUED MAPPINGS IN COMPLETE METRIC SPACES
}

\author{
JEONG SHEOK UME, BYUNG SOO LEE, and SUNG JIN CHO
}

Received 17 October 2001

Using the concept of $w$-distance, we improve some well-known fixed point theorems.

2000 Mathematics Subject Classification: 47H10.

1. Introduction. Recently, Ume [3] improved the fixed point theorems in a complete metric space using the concept of $w$-distance, introduced by Kada, Suzuki, and Takahashi [2], and more general contractive mappings than quasi-contractive mappings.

In this paper, using the concept of $w$-distance, we first prove common fixed point theorems for multivalued mappings in complete metric spaces, then these theorems are used to improve Ćirić's fixed point theorem [1], Kada-Suzuki-Takahashi's fixed point theorem [2], and Ume's fixed point theorem [3].

2. Preliminaries. Throughout, we denote by $\mathbb{N}$ the set of all positive integers and by $\mathbb{R}$ the set of all real numbers.

Definition 2.1 (see [2]). Let $(X, d)$ be a metric space, then a function $p: X \times X \rightarrow$ $[0, \infty)$ is called a $w$-distance on $X$ if the following are satisfied:

(1) $p(x, z) \leq p(x, y)+p(y, z)$ for all $x, y, z \in X$;

(2) for any $x \in X, p(x, \cdot): X \rightarrow[0, \infty)$ is lower semicontinuous;

(3) for any $\epsilon>0$, there exists $\delta>0$ such that $p(z, x) \leq \delta$ and $p(z, y) \leq \delta$ imply $d(x, y) \leq \epsilon$.

Definition 2.2. Let $(X, d)$ be a metric space with a $w$-distance $p$, then

(1) for any $x \in X$ and $A \subseteq X, d(x, A):=\inf \{d(x, y): y \in A\}$ and $d(A, x):=$ $\inf \{d(y, x): y \in A\}$

(2) for any $x \in X$ and $A \subseteq X, p(x, A):=\inf \{p(x, y): y \in A\}$ and $p(A, x):=$ $\inf \{p(y, x): y \in A\}$

(3) for any $A, B \subseteq X, p(A, B):=\inf \{p(x, y): x \in A, y \in B\}$;

(4) $C B_{p}(X)=\left\{A \mid A\right.$ is nonempty closed subset of $X$ and $\left.\sup _{x, y \in A} p(x, y)<\infty\right\}$.

The following lemmas are fundamental.

LEMMA 2.3 (see [2]). Let $X$ be a metric space with a metric $d$, let $p$ be a $w$-distance on $X$. Let $\left\{x_{n}\right\}$ and $\left\{y_{n}\right\}$ be sequences in $X$, let $\left\{\alpha_{n}\right\}$ and $\left\{\beta_{n}\right\}$ be sequences in $[0, \infty)$ converging to 0 , and let $x, y, z \in X$. Then the following hold: 
(1) if $p\left(x_{n}, y\right) \leq \alpha_{n}$ and $p\left(x_{n}, z\right) \leq \beta_{n}$ for any $n \in \mathbb{N}$, then $y=z$. In particular, if $p(x, y)=0$ and $p(x, z)=0$, then $y=z$;

(2) if $p\left(x_{n}, y_{n}\right) \leq \alpha_{n}$ and $p\left(x_{n}, z\right) \leq \beta_{n}$ for any $n \in \mathbb{N}$, then $\left\{y_{n}\right\}$ converges to $z$;

(3) if $p\left(x_{n}, x_{m}\right) \leq \alpha_{n}$ for any $n, m \in \mathbb{N}$ with $m>n$, then $\left\{x_{n}\right\}$ is a Cauchy sequence;

(4) if $p\left(y, x_{n}\right) \leq \alpha_{n}$ for any $n \in \mathbb{N}$, then $\left\{x_{n}\right\}$ is a Cauchy sequence.

LEMMA 2.4 (see [3]). Let $X$ be a metric space with a metric $d$, let $p$ be a $w$-distance on $X$, and let $T$ be a mapping of $X$ into itself satisfying

$$
p(T x, T y) \leq q \cdot \max \{p(x, y), p(x, T x), p(y, T y), p(x, T y), p(y, T x)\}
$$

for all $x, y \in X$ and some $q \in[0,1)$. Then

(1) for each $x \in X, n \in \mathbb{N}$, and $i, j \in \mathbb{N}$ with $i, j \leq n$,

$$
p\left(T^{i} x, T^{j} x\right) \leq q \cdot \delta(O(x, n))
$$

(2) for each $x \in X$ and $n \in \mathbb{N}$, there exist $k, l \in \mathbb{N}$ with $k, l \leq n$ such that

$$
\delta(O(x, n))=\max \left\{p(x, x), p\left(x, T^{k} x\right), p\left(T^{l} x, x\right)\right\}
$$

(3) for each $x \in X$,

$$
\delta(O(x, \infty)) \leq \frac{1}{1-q}\{p(x, x)+p(x, T x)+p(T x, x)\}
$$

(4) for each $x \in X,\left\{T^{n} x\right\}_{n=1}^{\infty}$ is a Cauchy sequence.

\section{Main results}

THEOREM 3.1. Let $X$ be a complete metric space with a metric $d$ and let $p$ be a $w$-distance on $X$. Suppose that $S$ and $T$ are two mappings of $X$ into $C B_{p}(X)$ and $\varphi$ : $X \times X \rightarrow[0, \infty)$ is a mapping such that

$$
\max \left\{p\left(u_{1}, u_{2}\right), p\left(v_{1}, v_{2}\right)\right\} \leq q \cdot \varphi(x, y)
$$

for all nonempty subsets $A, B$ of $X, u_{1} \in S A, u_{2} \in S^{2} A, v_{1} \in T B, v_{2} \in T^{2} B, x \in A$, $y \in B$, and some $q \in[0,1)$,

$$
\begin{gathered}
\sup \left\{\sup \left(\frac{\varphi(x, y)}{\min [p(x, S A), p(y, T B)]}: x \in A, y \in B\right): A, B \subseteq X\right\}<\frac{1}{q}, \\
\inf \{p(y, u)+p(x, S x)+p(y, T y): x, y \in X\}>0,
\end{gathered}
$$

for every $u \in X$ with $u \notin S u$ or $u \notin T u$, where $S A$ means $\bigcup_{a \in A} S a$. Then $S$ and $T$ have a common fixed point in $X$.

Proof. Let

$$
\beta=\sup \left\{\sup \left(\frac{\varphi(x, y)}{\min [p(x, S A), p(y, T B)]}: x \in A, y \in B\right): A, B \subseteq X\right\},
$$


and $k=\beta q$. Define $x_{n+1} \in S x_{n}$ and $y_{n+1} \in T y_{n}$ for all $n \in \mathbb{N}$. Then $x_{n} \in S x_{n-1}$, $x_{n+1} \in S^{2} x_{n-1}, y_{n} \in T y_{n-1}$, and $y_{n+1} \in T^{2} y_{n-1}$. From (3.1) and (3.2), we have

$$
\begin{aligned}
& p\left(x_{n}, x_{n+1}\right) \leq k p\left(x_{n-1}, x_{n}\right) \leq \cdots \leq k^{n-1} p\left(x_{1}, x_{2}\right), \\
& p\left(y_{n}, y_{n+1}\right) \leq k p\left(y_{n-1}, y_{n}\right) \leq \cdots \leq k^{n-1} p\left(y_{1}, y_{2}\right),
\end{aligned}
$$

for all $n \in \mathbb{N}$ and some $k \in[0,1)$. Let $n$ and $m$ be any positive integers such that $n<m$. Then, from (3.6), we obtain

$$
\begin{aligned}
p\left(y_{n}, y_{m}\right) & \leq p\left(y_{n}, y_{n+1}\right)+\cdots+p\left(y_{m-1}, y_{m}\right) \\
& =\sum_{i=0}^{m-n-1} p\left(y_{n+i}, y_{n+i+1}\right) \\
& \leq \sum_{i=0}^{m-n-1} k^{n+i-1} p\left(y_{1}, y_{2}\right) \\
& \leq \frac{k^{n-1}}{(1-k)} p\left(y_{1}, y_{2}\right) .
\end{aligned}
$$

By Lemma 2.3, $\left\{y_{n}\right\}$ is a Cauchy sequence. Since $X$ is complete, $\left\{y_{n}\right\}$ converges to $u \in X$. Then, since $p\left(y_{n}, \cdot\right)$ is lower semicontinuous, from (3.7) we have

$$
p\left(y_{n}, u\right) \leq \lim _{m \rightarrow \infty} \inf p\left(y_{n}, y_{m}\right) \leq \frac{k^{n-1}}{(1-k)} p\left(y_{1}, y_{2}\right) .
$$

Suppose that $u \notin S u$ or $u \notin T u$. Then, by (3.3), (3.5), (3.6), and (3.8), we have

$$
\begin{aligned}
0 & <\inf \{p(y, u)+p(x, S x)+p(y, T y): x, y \in X\} \\
& \leq \inf \left\{p\left(y_{n}, u\right)+p\left(x_{n}, x_{n+1}\right)+p\left(y_{n}, y_{n+1}\right): n \in \mathbb{N}\right\} \\
& \leq \inf \left\{\frac{k^{n-1}}{(1-k)} p\left(y_{1}, y_{2}\right)+k^{n-1} p\left(x_{1}, x_{2}\right)+k^{n-1} p\left(y_{1}, y_{2}\right): n \in \mathbb{N}\right\} \\
& =\left\{\frac{2-k}{(1-k)} p\left(y_{1}, y_{2}\right)+p\left(x_{1}, x_{2}\right)\right\} \inf \left\{k^{n-1}: n \in \mathbb{N}\right\} \\
& =0 .
\end{aligned}
$$

This is a contradiction. Therefore we have $u \in S u$ and $u \in T u$.

THEOREM 3.2. Let $X$ be a complete metric space with a metric $d$ and let $p$ be a $w$-distance on $X$. Suppose that $S$ and $T$ are two mappings of $X$ into $C B_{p}(X)$ and $\varphi$ : $X \times X \rightarrow[0, \infty)$ is a mapping such that

$$
\max \left\{p\left(u_{1}, u_{2}\right), p\left(v_{1}, v_{2}\right)\right\} \leq q \cdot \varphi(x, y)
$$

for all $x, y \in X, u_{1} \in S x, u_{2} \in S^{2} x, v_{1} \in T y, v_{2} \in T^{2} y$, and some $q \in[0,1)$,

$$
\sup \left\{\sup \left(\frac{\varphi(x, y)}{\min [p(x, S x), p(y, T y)]}: x \in A, y \in B\right): A, B \subseteq X\right\}<\frac{1}{q},
$$

and (3.3) is satisfied. Then $S$ and $T$ have a common fixed point in $X$. 
Proof. By a method similar to that in the proof of Theorem 3.1, the result follows.

THEOREM 3.3. Let $X$ be a complete metric space with a metric $d$ and let $p$ be a $w$-distance on $X$. Suppose that $T$ is a mapping of $X$ into $C B_{p}(X)$ and $\psi: X \rightarrow[0, \infty)$ is a mapping such that

$$
p\left(u_{1}, u_{2}\right) \leq q \cdot \psi(x)
$$

for all $x \in X, u_{1} \in T x, u_{2} \in T^{2} x$ and some $q \in[0,1)$,

$$
\begin{gathered}
\sup \left\{\frac{\psi(x)}{p(x, T x)}: x \in X\right\}<\frac{1}{q}, \\
\inf \{p(x, u)+p(x, T x): x \in X\}>0,
\end{gathered}
$$

for every $u \in X$ with $u \notin T u$. Then $T$ has a fixed point in $X$.

Proof. By a method similar to that in the proof of Theorem 3.1, the result follows.

THEOREM 3.4. Let $X$ be a complete metric space with a metric $d$ and let $p$ be a $w$-distance on $X$. Suppose that $S$ and $T$ are self-mapping of $X$ and $\varphi: X \times X \rightarrow[0, \infty)$ is a mapping such that

$$
\max \left\{p\left(S x, S^{2} x\right), p\left(T y, T^{2} y\right)\right\} \leq q \cdot \varphi(x, y)
$$

for all $x, y \in X$ and some $q \in[0,1)$,

$$
\begin{gathered}
\sup \left\{\frac{\varphi(x, y)}{\min [p(x, S x), p(y, T y)]}: x, y \in X\right\}<\frac{1}{q}, \\
\inf \{p(y, u)+p(x, S x)+p(y, T y): x, y \in X\}>0,
\end{gathered}
$$

for every $u \in X$ with $u \neq S u$ or $u \neq T u$. Then $S$ and $T$ have a common fixed point in $X$.

Proof. By a method similar to that in the proof of Theorem 3.1, the result follows.

From Theorem 3.1, we have the following corollary.

COROLlarY 3.5. Let $X$ be a complete metric space with a metric $d$ and let $p$ be a $w$-distance on $X$. Suppose that $S$ and $T$ are two mappings of $X$ into $C B_{p}(X)$ and $\varphi: X \times X \rightarrow[0, \infty)$ is a mapping such that

$$
\begin{aligned}
\max \{ & \sup \left[p\left(u_{1}, u_{2}\right): u_{1} \in S x, u_{2} \in S^{2} x\right] \\
& \left.\sup \left[p\left(v_{1}, v_{2}\right): v_{1} \in T x, v_{2} \in T^{2} x\right]\right\} \leq q \cdot \varphi(x, y)
\end{aligned}
$$

for all $x, y \in X$ and some $q \in[0,1)$, and that (3.3) and (3.11) are satisfied. Then $S$ and $T$ have a common fixed point in $X$. 
From Theorem 3.3, we have the following corollaries.

COROLLARY 3.6. Let $X$ be a complete metric space with a metric $d$ and let $p$ be a $w$-distance on $X$. Suppose that $T$ is a mapping of $X$ into $C B_{p}(X)$ and $\psi: X \rightarrow[0, \infty)$ is a mapping such that

$$
\sup \left[p\left(u_{1}, u_{2}\right): u_{1} \in T x, u_{2} \in T^{2} x\right] \leq q \cdot \psi(x)
$$

for all $x \in X$ and some $q \in[0,1)$, and that (3.13) is satisfied. Then $T$ has a fixed point in $X$.

COROLLARY 3.7. Let $X$ be a complete metric space with a metric $d$ and let $p$ be a $w$-distance on $X$. Suppose that $T$ is a self-mapping of $X$ and $\psi: X \rightarrow[0, \infty)$ is a mapping such that

$$
p\left(T x, T^{2} x\right) \leq q \cdot \psi(x)
$$

for all $x \in X$ and some $q \in[0,1)$,

$$
\begin{gathered}
\sup \left\{\frac{\psi(x)}{p(x, T x)}: x \in X\right\}<\frac{1}{q}, \\
\inf \{p(x, u)+p(x, T x): x \in X\}>0,
\end{gathered}
$$

for every $u \in X$ with $u \neq T u$. Then $T$ has a fixed point in $X$.

From Corollary 3.7, we have the following corollaries.

COROllary 3.8 (see [3]). Let $X$ be a complete metric space with a metric $d$ and let $p$ be a $w$-distance on $X$. Suppose that $T$ is a self-mapping of $X$ such that

$$
p(T x, T y) \leq q \cdot \max \{p(x, y), p(x, T x), p(y, T y), p(x, T y), p(y, T x)\}
$$

for all $x, y \in X$ and some $q \in[0,1)$, and that

$$
\inf \{p(x, u)+p(x, T x): x \in X\}>0
$$

for every $u \in X$ with $u \neq T u$. Then $T$ has a unique fixed point in $X$.

Proof. By (3.20) and Lemma 2.4(3), we have

$$
\sup \left\{p\left(T^{i} x, T^{j} x\right) \mid i, j \in \mathbb{N} \cup\{0\}\right\}<\infty
$$

for every $x \in X$. Thus we may define a function $r: X \times X \rightarrow[0, \infty)$ by

$$
r(x, y)=\max \left\{\sup \left[p\left(T^{i} x, T^{j} x\right) \mid i, j \in \mathbb{N} \cup\{0\}\right], p(x, y)\right\}
$$

for every $x, y \in X$. Clearly, $r$ is a $w$-distance on $X$. Let $x$ be a given element of $X$, then, by using Lemma 2.4(1), (3.20), and (3.23), we have

$$
\begin{aligned}
r\left(T x, T^{2} x\right) & =\sup \left\{p\left(T^{i} x, T^{j} x\right) \mid i, j \in \mathbb{N}\right\} \\
& \leq q \cdot \sup \left\{p\left(T^{i} x, T^{j} x\right) \mid i, j \in \mathbb{N} \cup\{0\}\right\} \\
& =q \cdot r(x, T x) .
\end{aligned}
$$


By (3.21) and (3.23), we obtain

$$
\inf \{r(x, u)+r(x, T x): x \in X\}>0
$$

for every $u \in X$ with $u \neq T u$. From (3.24), (3.25), and Corollary 3.7, $T$ has a fixed point in $X$. By (3.20) and Lemma 2.4, it is clear that the fixed point of $T$ is unique.

COROLlary 3.9 (see [2]). Let $X$ be a complete metric space, let $p$ be a $w$-distance on $X$, and let $T$ be a mapping from $X$ into itself. Suppose that there exists $q \in[0,1)$ such that

$$
p\left(T x, T^{2} x\right) \leq q \cdot p(x, T x)
$$

for every $x \in X$ and that

$$
\inf \{p(x, y)+p(x, T x): x \in X\}>0
$$

for every $y \in X$ with $y \neq T y$. Then $T$ has a fixed point in $X$.

Proof. Define $\psi: X \rightarrow[0, \infty)$ by

$$
\psi(x)=p(x, T x)
$$

for all $x \in X$. Thus the conditions of Corollary 3.7 are satisfied. Hence $T$ has a fixed point in $X$.

From Corollary 3.8, we have the following corollary.

COROLlary 3.10 (see [1]). Let $X$ be a complete metric space with a metric $d$ and let $T$ be a mapping from $X$ into itself. Suppose that $T$ is a quasicontraction, that is, there exists $q \in[0,1)$ such that

$$
d(T x, T y) \leq q \cdot \max \{d(x, y), d(x, T x), d(y, T y), d(x, T y), d(y, T x)\}
$$

for every $x, y \in X$. Then $T$ has a unique fixed point in $X$.

Proof. It is clear that the metric $d$ is a $w$-distance and

$$
\inf \{d(x, y)+d(x, T x): x \in X\}>0
$$

for every $y \in X$ with $y \neq T y$. Thus, by Corollary 3.8 or 3.9 , $T$ has a unique fixed point in $X$.

ACKNOWLEDGMENT. This work was supported by grant No. 2001-1-10100-005-2 from the Basic Research Program of the Korea Science \& Engineering Foundation.

\section{REFERENCES}

[1] L. B. Ćirić, A generalization of Banach's contraction principle, Proc. Amer. Math. Soc. 45 (1974), 267-273.

[2] O. Kada, T. Suzuki, and W. Takahashi, Nonconvex minimization theorems and fixed point theorems in complete metric spaces, Math. Japon. 44 (1996), no. 2, 381-391. 
[3] J. S. Ume, Fixed point theorems related to Ćirić's contraction principle, J. Math. Anal. Appl. 225 (1998), no. 2, 630-640.

JeONG Sheok Ume: DePartment of APPlied Mathematics, Changwon National UniVERSITY, CHANGWON 641-773, KOREA

E-mail address: jsume@sarim. changwon.ac.kr

Byung Soo LeE: Department of MATHematics, Kyungsung University, PusAn 608-736, KOREA

E-mail address: bslee@star. kyungsung.ac.kr

Sung Jin Cho: Department of Applied Mathematics, Pukyong National University, PUSAN 608-737, KOREA

E-mail address: sjcho@dolphin.pknu.ac.kr 


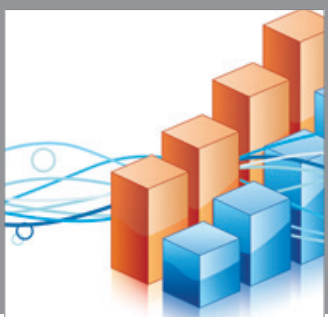

Advances in

Operations Research

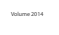

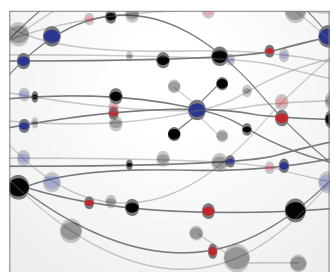

\section{The Scientific} World Journal
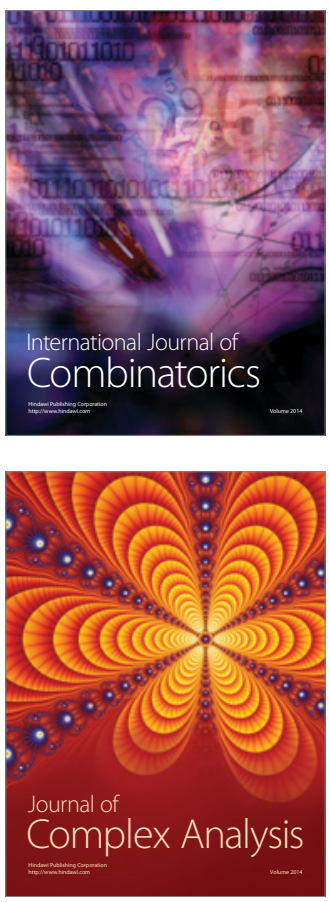

International Journal of

Mathematics and

Mathematical

Sciences
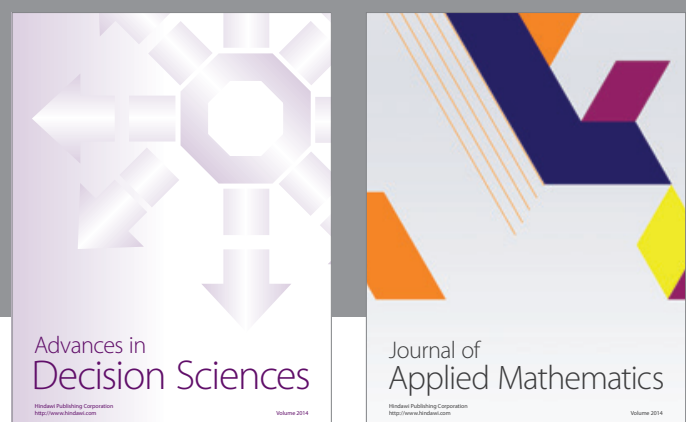

Journal of

Applied Mathematics
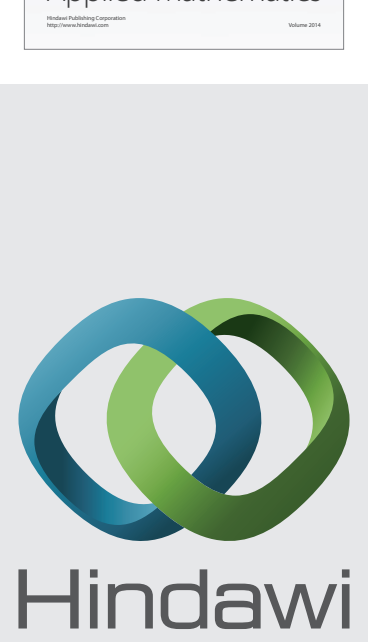

Submit your manuscripts at http://www.hindawi.com
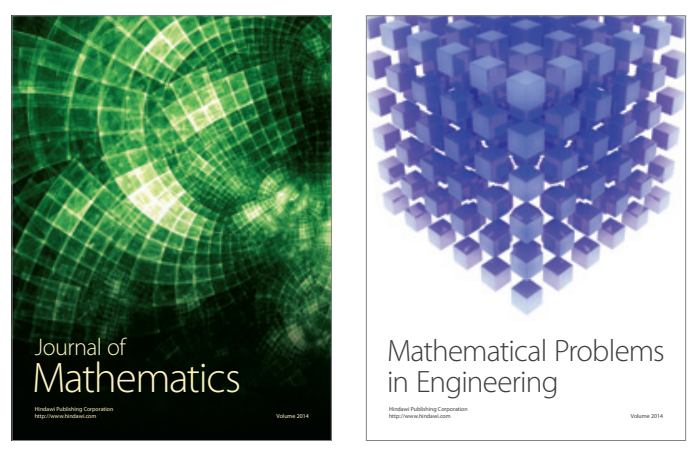

Mathematical Problems in Engineering
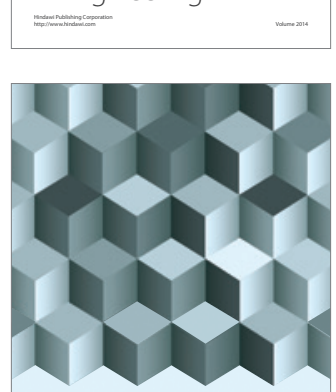

Journal of

Function Spaces
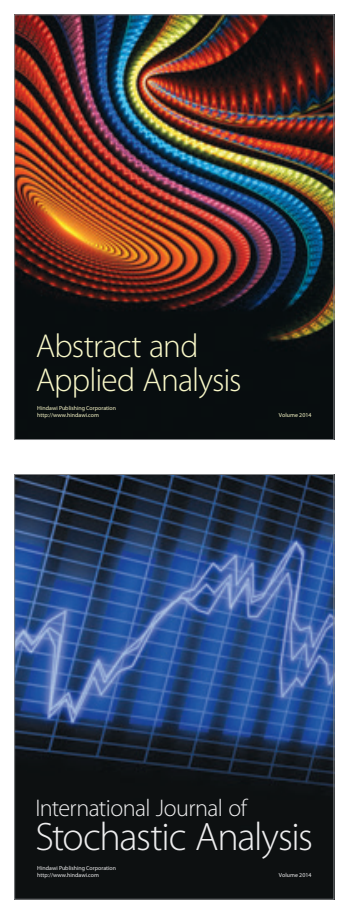

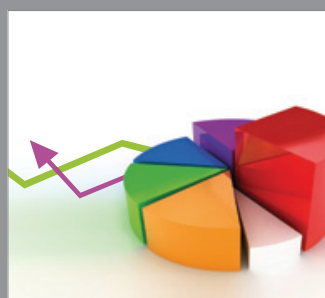

ournal of

Probability and Statistics

Promensencen
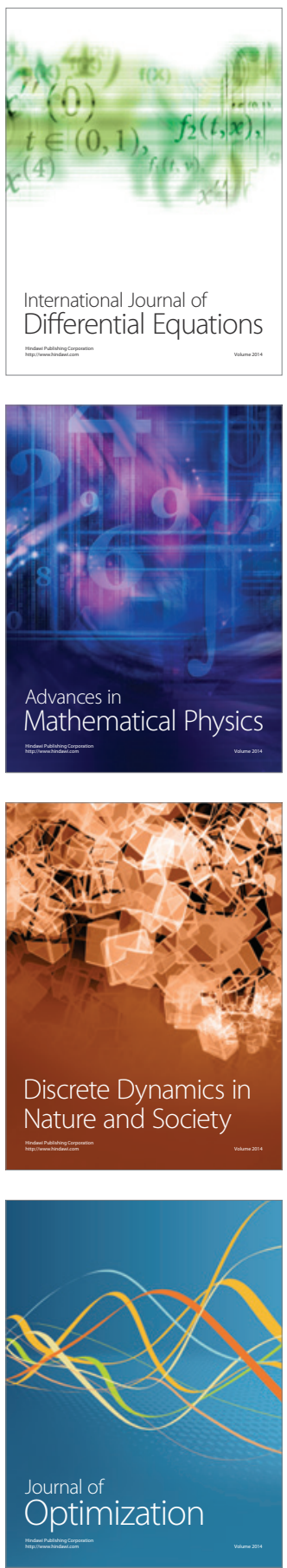